\title{
The effects of different calibration and frequency response correction methods on eddy covariance ozone flux measured with a dry chemiluminescence analyzer
}

\author{
Zhilin Zhu ${ }^{\mathrm{a}, *}$, Fenghua Zhao ${ }^{\mathrm{a}}$, Linda Voss ${ }^{\mathrm{b}}$, Liukang Xu ${ }^{\mathrm{c}}$, Xiaomin Sun ${ }^{\mathrm{a}}$, Guirui $\mathrm{Yu}^{\mathrm{a}}$, \\ Franz X. Meixner ${ }^{b}$ \\ a Key Laboratory of Ecosystem Network Observation and Modeling, Institute of Geographic Sciences and Natural Resources Research, Chinese Academy of \\ Sciences, Beijing 100101, China \\ b Biogeochemistry Department, Max Planck Institute for Chemistry, Mainz 55128, Germany \\ ${ }^{\mathrm{c}}$ LI-COR Biosciences, Lincoln, NE 68504, USA
}

\section{A R T I C L E I N F O}

\section{Article history:}

Received 19 June 2015

Accepted 24 June 2015

Available online 8 July 2015

\section{Keywords:}

Ozone flux

Eddy covariance

Fast-response ozone analyzer

Spectral analysis

Frequency response correction

Calibration methods

\begin{abstract}
A B S T R A C T
Ozone $\left(\mathrm{O}_{3}\right)$ flux $\left(F_{0}\right)$ was measured over a wheat field in Yucheng, China, using the eddy covariance technique. A dry chemiluminescence fast-response $\mathrm{O}_{3}$ analyzer and a UV-absorption based slow-response $\mathrm{O}_{3}$ analyzer were used for measuring fast $\mathrm{O}_{3}$ concentration fluctuations and absolute concentrations, respectively. The main objective of this study was to determine a group of suitable methods for calculating $F_{\mathrm{o}}$ based on the performance of the two $\mathrm{O}_{3}$ analyzers in the field. We evaluated the effects of three calibration methods on $F_{0}$. These calibration methods include the ratio method (RM, it assumes that the fast-response analyzer's signal-output is directly proportional to absolute ambient $\mathrm{O}_{3}$ concentration within a 30-min interval), the ratio offset method (ROM, it is based on the ratio method with analyzer's offset modification), and the ratio variation method (RVM, it is based on the ratio method with the fastresponse analyzer's gain factor variation within a 30-min interval). Three frequency response corrections (analytic, revised analytic, and in-situ) for the estimation of $F_{\mathrm{o}}$ were also evaluated. Our results show that: (1) Compared to the $\mathrm{O}_{3}$ flux with the commonly-used method (RM), on average, the fluxes with ROM and RVM were decreased by about $9 \%$ and $7 \%$, respectively. (2) Based on the spectral analysis, the fastresponse $\mathrm{O}_{3}$ analyzer's noise could cause random errors, but did not result in a systematic error in $F_{0}$. Tubing attenuation in $\mathrm{O}_{3}$ concentration fluctuations can cause up to $20 \%$ loss in $F_{0}$. (3) Frequency response corrections for $F_{\mathrm{o}}$ with the original analytic method, the in-situ method, and the revised analytic method were $34.6 \%, 23.8 \%$ and $25.4 \%$ on average, respectively.
\end{abstract}

(c) 2015 Elsevier B.V. All rights reserved.

\section{Introduction}

Atmospheric ozone $\left(\mathrm{O}_{3}\right)$ near the ground is a major pollutant and its adverse effects on plant growth, photosynthesis and yield have been reported for many decades (Pleijel et al., 2004; Feng et al., 2008). With rapid industrialization and urbanization in China, the increase of atmospheric $\mathrm{O}_{3}$ concentration has the potential to significantly reduce crop yields (Wang et al., 2007). Currently, $\mathrm{O}_{3}$ concentration-based and flux-based indexes have been proposed to assess the impact of $\mathrm{O}_{3}$ on crop ecophysiology (Musselman et al.,

\footnotetext{
* Corresponding author at: Institute of Geographic Sciences and Natural Resources Research, Chinese Academy of Sciences, 11 A Datun Rd., Chaoyang district, Beijing 100101, China. Fax: +86 1064858099.

E-mail address: zhuzl@igsnrr.ac.cn (Z.Zhu).
}

2006). These $\mathrm{O}_{3}$ concentration-based indexes do not consider the status of vegetation and ecosystem, e.g. leaf area index and stomatal conductance, and only provide an indirect measure of the effects of $\mathrm{O}_{3}$. Direct $\mathrm{O}_{3}$ flux measurements could provide a better criterion for evaluating the influence of $\mathrm{O}_{3}$ on vegetation and ecosystem (Pleijel et al., 2004; Mills et al., 2011). Since the total ecosystem $\mathrm{O}_{3}$ flux is caused by both, stomatal and non-stomatal uptake, one of the common methods is to use a model to partition the total ecosystem $F_{0}$ estimate into stomatal and non-stomatal portion (Lamaud et al., 2009; Turnipseed et al., 2009; Fares et al., 2012). Hence, high-quality field $\mathrm{O}_{3}$ flux measurements are essential to develop flux-based indexes and process-based $\mathrm{O}_{3}$ flux models.

In recent decades, some micrometeorological techniques, such as aerodynamic gradient method (Galbally, 1971; Muller et al., 2009; Loubet et al., 2013), modified Bowen ratio method (Leuning et al., 1979; Mayer et al., 2011) and quasi-eddy covariance 
technique (Wohlfahrt et al., 2009), have been used to measure $\mathrm{O}_{3}$ flux. Although a fast-response $\mathrm{O}_{3}$ sensor was not needed, all those methods were indirectly measured based on the various assumptions (Grünhage et al., 2000). Being the most direct and least invasive method, the eddy covariance method is commonly considered to be the best technique for flux measurement, and has been widely used to measure biosphere-atmosphere exchanges of carbon dioxide and water vapor (Aubinet et al., 2000; Baldocchi et al., 2001). This is probably due to the continuous improvement of commercially available fast-response gas analyzers for $\mathrm{CO}_{2}$ and $\mathrm{H}_{2} \mathrm{O}$ (closed-path and open-path instruments) and the capability to perform fully automated eddy covariance measurements in the field (Baldocchi, 2003; Burba et al., 2010, 2012). The same cannot be said for other trace gas flux measurements, such as $\mathrm{O}_{3}$ flux. One of the main reasons is the lack of robust and high performance fastresponse $\mathrm{O}_{3}$ gas analyzers which can be deployed in the field on a long-term basis. Therefore, further research is needed to evaluate the performance and feasibility of a fast-response $\mathrm{O}_{3}$ sensor for eddy covariance flux measurement in the field conditions.

Only a few commercially available analyzers exist for fastresponse ozone measurements (Ray et al., 1986; Güsten et al., 1992; Zahn et al., 2012). All of them are so-called "closed-path" instruments, and most of them are custom-built and have been used in the field for short time periods (Yushkov et al., 1999; Kurpius et al., 2002; Coyle et al., 2009; Muller et al., 2009, 2010). Gasphase chemiluminescence techniques have been used to measure turbulent, total ecosystem $\mathrm{O}_{3}$ fluxes. These techniques are based on the detection of the chemiluminescence of $\mathrm{O}_{3}$ reacting with organic dyes adsorbed on a solid disc (Güsten et al., 1992; Ermel et al., 2013). Although the response time of the latter technique can be as fast as $0.1 \mathrm{~s}$, signal stability suffers a drift and degradation over time (Muller et al., 2010). To keep its high sensitivity, the dye covered disc has to be replaced every few days. Recently, Karlsruhe Institute of Technology and Enviscope GmbH (Germany) have cooperatively developed a new fast-response $\mathrm{O}_{3}$ analyzer (Zahn et al., 2012, hereafter referred to as ENVI), which can be considered as an improved version of the analyzer originally developed by Güsten et al. (1992). Moreover, very recently, Ermel et al. (2013) have reported on a new preparation method for sensor discs suitable for ENVI measurements, which has greatly improved the stability and performance of sensor discs. Although the excellent performance of the ENVI instrument has been demonstrated by laboratory experiments (Zahn et al., 2012), its performance under field condition requires evaluation, especially its spectral characteristics and the relationship between its signal-output and the ambient $\mathrm{O}_{3}$ concentration.

In principle, the procedures involved in the eddy covariance $\mathrm{O}_{3}$ flux calculation are the same as those for $\mathrm{CO}_{2} / \mathrm{H}_{2} \mathrm{O}$ fluxes. Different methods and using different parameters in those procedures could result in a certain degree of uncertainty for the final flux (Massman and Lee, 2002). For example, how to determine the lag time of a closed-path system? What is the suitable method for correcting the effect of air density fluctuation on ozone flux (Webb et al., 1980)? How does the analyzer perform in the range of high and low frequencies, and how to correct the flux loss due to high-frequency attenuation or noise?

Frequency response corrections are among the most complicated correction in eddy covariance data processing. Moore (1986) summarized earlier results and gave a series of equations to estimate the frequency loss due to different processes. Since then, many other researchers developed or improved some new frequency response correction methods (Moncrieff et al., 1997; Massman, 2000; Ibrom et al., 2007; Fratini et al., 2012), which in turn result in different $F_{\mathrm{o}}$ values. Basically, there are two categories of spectral correction methods, the spectral theoretical transfer function method and the in-situ method (Massman and Clement,
2004). Especially for a closed-path system, the effect of tubing attenuation on flux can be significant (Leuning and Moncrieff, 1990; Massman, 1991).

Another very specific source of uncertainty for $F_{0}$ is how to convert the fast-response $\mathrm{O}_{3}$ analyzer's signal-output (in $\mathrm{mV}$ ) into $\mathrm{O}_{3}$ concentration. Despite the low stability character of the ENVI signal-output, ENVI data represent fast fluctuations quite well, but not the true mean value of the ambient $\mathrm{O}_{3}$ concentrations. Consequently, the ambient $\mathrm{O}_{3}$ concentration may be measured with a co-located slow-response $\mathrm{O}_{3}$ analyzer. For considerably short time intervals (a couple of minutes), however, we can assume that the ENVI's signal-output is proportional to absolute $\mathrm{O}_{3}$ concentration. For longer time periods (a couple of hours and more), this may not be the case. Thus, uncertainties will be produced when calculating $F_{0}$ using different calibration methods (Muller et al., 2010).

In this paper, we evaluate the field performance of the ENVI $\mathrm{O}_{3}$ analyzer and the effects of different correction methods on the $\mathrm{O}_{3}$ flux. The main motivation was to explore a group of suitable methods or optimal parameters for calculating $F_{0}$. The specific objectives of our study are: (1) to analyze the effect of different unit conversion (calibration) methods on $F_{0}$; (2) to evaluate the field performance of the analyzer; and (3) to determine the appropriate frequency response correction methods.

\section{Materials and methods}

\subsection{Site}

The field experiment was conducted over a winter wheat field at the Yucheng Comprehensive Experiment Station of the Chinese Academy of Science ( $36^{\circ} 50^{\prime} \mathrm{N}, 116^{\circ} 34^{\prime} \mathrm{E}, 28 \mathrm{~m}$ a.s.l.; Shandong Province, China). The site is located in the Yellow River alluvial plain of the North China Plain, characterized by loamy soil texture, semiarid, and warm temperate climate. The mean annual temperature and precipitation are $13.4^{\circ} \mathrm{C}$ and $567 \mathrm{~mm}$, respectively. The main growing season of winter wheat is from mid-March to early June. The experimental site is relatively flat, and fetch requirements for eddy covariance measurements are well satisfied within $200 \mathrm{~m}$ around the instruments' location. The canopy height of the winter wheat increased from $0.05 \mathrm{~m}$ to $0.75 \mathrm{~m}$ during the duration of the field experiment (7 March-7 June, 2012).

\subsection{Instruments and observations}

$\mathrm{O}_{3}$ flux was measured with the eddy covariance method, in combination with observations of the Chinese Terrestrial Ecosystem Flux Observational Research Network (ChinaFLUX) (Yu et al., 2006). The instrumentation includes a 3D sonic anemometer (CSAT3, Campbell Scientific Instrument, UT, USA) and an openpath $\mathrm{CO}_{2} / \mathrm{H}_{2} \mathrm{O}$ gas analyzer (LI-7500, LI-COR Biosciences, NE, USA) for measuring sensible heat, latent heat, and $\mathrm{CO}_{2}$ fluxes. The $\mathrm{O}_{3}$ concentration fluctuation was measured by ENVI. It is a closedpath analyzer, in which air was drawn down through a $3 \mathrm{~m}$ long with $4 \mathrm{~mm}$ I.D. PTFE (Teflon) tube at a flow rate of $0.81 \mathrm{~min}^{-1}$ (Reynolds number was about 330) and passed over a small disc coated with $\mathrm{O}_{3}$-sensitive dye. The mean delay time of air through the tube was about $2.8 \mathrm{~s}$, which was calculated by the maximum covariance method. The ENVI's output signal (in $\mathrm{mV}$ ) was positively correlated with the ambient $\mathrm{O}_{3}$ concentration. To calibrate the ENVI's signal-output, the ambient $\mathrm{O}_{3}$ absolute concentration was measured with a slow-response portable UV-absorption based $\mathrm{O}_{3}$ analyzer (Model 205, 2B Technologies Inc., Co., USA; hereafter as M205). This analyzer has a detection limit of $1 \mathrm{ppb}$ and outputs mean $\mathrm{O}_{3}$ concentration for every $2 \mathrm{~s}$. The intake tubing was the same size as described above. Micrometeorological and radiation 
variables were also measured, including air temperature and relative humidity (HMP45C, Vaisala Co., Finland), wind speed (A100R, Vector Instruments, UK), net radiation (CNR1, Kipp \& Zonen, The Netherlands), and photosynthetically active radiation (LI-190SB, LI-COR Biosciences, NE, USA). All sensors were installed at $2.2 \mathrm{~m}$ height.

The sampling frequency was $10 \mathrm{~Hz}$. Two gas intake tubes were mounted next to the sonic anemometer center with horizontal separation $0.2 \mathrm{~m}$. Given the continuous consumption of organic dye, ENVI's sensitivity slowly decreased with time. To maintain its high sensitivity, we replaced the organic dye disc every 3-4 days. $10 \mathrm{~Hz}$ raw data from the EC system were recorded into 30-min interval files on a data-logger (CR5000, Campbell Scientific Instrument, UT, USA). All fluxes and covariances were calculated using a block averaging period of $30-\mathrm{min}$.

\subsection{Calibration methods, spectral analysis and spectral corrections}

\subsubsection{Calibration methods}

Studying calibration methods is equivalent to the exploration of the most suitable unit conversion model and parameters based on the analyzer's performance. For $\mathrm{CO}_{2} / \mathrm{H}_{2} \mathrm{O}$ gas analyzer instruments, it is relatively straightforward, as their gain and offset are relatively stable for long periods (Burba et al., 2010). However, for ENVI, this step is more complex. This is because the stability of ENVI is affected by the consumption of ozone-sensitive dye and environmental conditions, which results in the nonlinear relationship between the ENVI's voltage output and $\mathrm{O}_{3}$ concentration. Therefore, ENVI's raw data cannot be directly used to compute the $\mathrm{O}_{3}$ flux with vertical wind speed from the sonic anemometer. To calculate $F_{0}$, we must first select a suitable calibration method (i.e. how to convert voltage into absolute $\mathrm{O}_{3}$ concentration data).

2.3.1.1. Ratio method (RM). For preliminary calculation, it is justified that the sensitivity change is negligible over a 30-min averaging interval and that the ENVI's signal output $X(\mathrm{mV})$ is proportional to the ambient ozone concentration (Coyle et al., 2009; Muller et al., 2009). An estimate of $10 \mathrm{~Hz} \mathrm{O}_{3}$ concentration data $\left(\hat{C}_{\mathrm{oi}}\right)$ can be calculated as

$\hat{C}_{\mathrm{oi}}=G_{\mathrm{RM}} X_{\mathrm{i}}$

where $G_{\mathrm{RM}}\left(\mu \mathrm{g} \mathrm{m}^{-3} \mathrm{mV}^{-1}\right)$ is the gain factor of the RM, which is

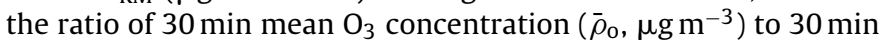
mean voltage output of $\operatorname{ENVI}(\bar{X}, \mathrm{mV})$, i.e. $\bar{\rho}_{\mathrm{o}} / \bar{X}$. The raw $F_{\mathrm{o}}$ can be given as

$F_{\mathrm{O} \_\mathrm{RM}}=w^{\prime} \hat{C}_{\mathrm{o}}^{\prime}=G_{\mathrm{RM}} w^{\prime} X^{\prime}=\bar{\rho}_{\mathrm{o}} \frac{w^{\prime} X^{\prime}}{\bar{X}}=\bar{\chi}_{\mathrm{o}} \frac{P}{T} \frac{M_{\mathrm{o}}}{R} \frac{w^{\prime} X^{\prime}}{\bar{X}}$

where $\bar{\chi}_{0}$ is mean $\mathrm{O}_{3}$ mixing ratio by $\mathrm{M} 205$ ( $\mathrm{nmol} \mathrm{mol}{ }^{-1}$ or ppbv); $P, T, R$ and $M_{\mathrm{o}}$ are barometric pressure (Pa), air temperature $(K)$, ideal gas constant $\left(8.314 \mathrm{~Pa} \mathrm{~m}^{3} \mathrm{~K}^{-1} \mathrm{~mol}^{-1}\right)$ and molar mass of $\mathrm{O}_{3}$ $\left(48 \mathrm{~g} \mathrm{~mol}^{-1}\right)$, respectively.

2.3.1.2. Ratio offset method (ROM). Although the ratio method is the most widely used to calibrate the fast-response $\mathrm{O}_{3}$ analyzer, it does not consider the potential zero-drift. Assuming that ENVI has a fixed zero-offset, defined as the mean voltage output at zero $\mathrm{O}_{3}$ concentration (Muller et al., 2010), the estimates $\left(\hat{C}_{\mathrm{oi}}\right)$ can be obtained by ROM as

$\hat{C}_{\mathrm{oi}}=G_{\mathrm{ROM}}\left(X_{\mathrm{i}}-c\right)$ where $G_{\mathrm{ROM}}$ is the gain factor of the ROM, equal to $\bar{\rho}_{\mathrm{o}} /(\bar{X}-c)$, and offset $c$ can be obtained by the following equation

$c=\frac{\sum X_{j} \sum \rho_{\mathrm{oj}}^{2}-\sum X_{j} \rho_{\mathrm{oj}} \sum \rho_{\mathrm{oj}}}{N \sum \rho_{\mathrm{oj}}^{2}-\left(\sum \rho_{\mathrm{oj}}\right)^{2}}$

where the number of values from $j=1$ to $N$ represents each $30 \mathrm{~min}$ mean data in one disc period. Muller et al. (2010) used 15 min mean data to calculate $c$. In fact, $c$ is the intercept of the linear regression between $\bar{\rho}_{0}$ against $\bar{X}$. Considering the offset might change from disc to disc, an offset value was just used for one disc period. Then, $F_{\mathrm{o}}$ can be obtained as

$F_{\mathrm{O} \_\mathrm{ROM}}=G_{\mathrm{ROM}} w^{\prime} X^{\prime}=\frac{\bar{X}}{\bar{X}-c} F_{\mathrm{O} \_\mathrm{RM}}$

2.3.1.3. Ratio variation method (RVM). Strictly speaking, the ENVI's gain factor is changing all the time. However, both RM and ROM assume that the gain factors were fixed within a 30 -min period. This assumption may not be the case. Considering the potential variation of gain factor within a $30 \mathrm{~min}$ period, based on the assumption of the RM, the estimates $\left(\hat{C}_{\mathrm{oi}}\right)$ within the optimal averaging time $\left(T_{\mathrm{opt}}\right)$ can be estimated by

$\hat{C}_{\mathrm{oi}}=G\left(T_{\mathrm{opt}}\right) X_{\mathrm{i}}$

where $G\left(T_{\mathrm{opt}}\right)$ is the mean gain factor in $T_{\text {opt }}$ periods, equal to $\rho_{\mathrm{o}}\left(\bar{T}_{\mathrm{opt}}\right) / X\left(\bar{T}_{\mathrm{opt}}\right)$. The key issue of this method is how to determine $T_{\text {opt }}$. Once the estimates of $\mathrm{O}_{3}$ concentration fluctuation were determined, the 30 min mean $F_{0}$ can be calculated by the normal eddy covariance method.

In this study, the Allan-Werle variance (hereafter referred to as AW variance) method (Allan, 1966; Werle et al., 1993) was used to determine the optimal averaging time. Here, we briefly describe the calculation of the Allan-Werle variance. We selected $N$ pairs $10 \mathrm{~Hz}$ raw data of M205 and ENVI during the daytime. These values were divided into $M$ groups, and each group contained $k$ pairs data. The gain factor $G_{i}(k)$ in the group $i$ was the ratio of the mean $\mathrm{O}_{3}$ concentration to mean $X$. The Allan-Werle variance can be calculated by

$\sigma^{2}(\tau)=\frac{1}{2 M} \sum_{i=1}^{M}\left[G_{i+1}(k)-G_{i}(k)\right]^{2}, \quad M=N / k-1$

The AW variance was then plotted with the averaging time $\tau$ in a $\log -\log$ scale and the optimal averaging time was estimated.

\subsubsection{Power spectra and co-spectra calculations}

Power spectra and co-spectra were calculated by Fast Fourier Transform (FFT) method with the EddyPro ${ }^{\circledR}$ Software package. For each half hour of the $10 \mathrm{~Hz}$ raw data, the FFT produced a set of power spectra or co-spectra (with vertical velocity $w$ ) at a range of frequencies. The range is defined by the 30 min periods and $10 \mathrm{~Hz}$ sampling frequency. For comparing spectral distributions of different scalars, all spectra were normalized by their total variances or covariances. To smooth the changes of spectral shapes, we used binned spectral densities for analyzing spectral characteristic of all scalars.

\subsubsection{Co-spectra accumulation (Ogive)}

The cumulative co-spectrum from high to low frequencies, which is often called an Ogive is more suitable for quantitatively analyzing the relative contribution from different frequencies to the total flux (Sun et al., 2006). The Ogive is defined as

$\operatorname{Og}_{w s}(f)=\int_{f_{\mathrm{Nyq}}}^{f} \operatorname{Co}_{w s}(f) \mathrm{d} f$ 
where $f$ is the natural frequency and $f_{\mathrm{Nyq}}$ is the Nyquist frequency (half of the sampling frequency, $5 \mathrm{~Hz}$ in this study), $\mathrm{Co}_{\mathrm{ws}}$ is the cospectrum between vertical velocity $w$ and a particular scalar $s$. The cumulative co-spectrum of all frequencies is proportional to the covariance of the corresponding time series.

\subsubsection{Frequency response correction}

Flux loss due to inadequate frequency response can be corrected by multiplying the measured fluxes with a frequency response correction factor $(C F, \geq 1)$. Massman and Clement (2004) summarized the previous studies and gave the following equation.

$\mathrm{CF}=\frac{w^{\prime} s^{\prime}}{\overline{w^{\prime} s^{\prime} m}}=\frac{\int_{0}^{\infty} \operatorname{Co}_{\mathrm{ws}}(f) \mathrm{d} f}{\int_{0}^{\infty}\left[1-\sin ^{2}\left(\pi f T_{\mathrm{b}}\right) /\left(\pi \mathrm{f} T_{\mathrm{b}}\right)^{2}\right] H(f) \operatorname{Co}_{\mathrm{ws}}(f) \mathrm{d} f}$

where $\overline{w^{\prime} S^{\prime}} \mathrm{m}$ is the measured covariance, $\overline{w^{\prime}} S^{\prime}$ is the true covariance, $T_{b}$ is the block averaging period, $f$ is natural frequency and $\left[1-\sin ^{2}\left(\pi f T_{\mathrm{b}}\right) /\left(\pi f \mathrm{~T}_{b}\right)^{2}\right]$ is the transfer function for the low frequency loss. $\mathrm{Co}_{\mathrm{ws}}(f)$ is the reference co-spectrum, which can be taken from a theoretical co-spectrum (Kaimal and Finnigan, 1994) or from an in-situ specific reference co-spectrum (Ibrom et al., 2007). The high frequency transfer function $H(f)$ can be estimated by theoretical methods, in-situ methods, or their combinations (Moncrieff et al., 1997; Aubinet et al., 2000; Ibrom et al., 2007).

2.3.4.1. Analytic transfer function method. In the EddyPro ${ }^{\circledR}$ software package (LI-COR, 2013), only one purely analytic transfer function method is provided. The algorithms were adopted from Moncrieff et al. (1997), hereafter M97. According to the literature, $H(f)$ is the convolution of a series of transfer functions associated with high frequency losses and can be expressed as

$H(f)=T_{\mathrm{r}}(f) T_{\mathrm{d}(\text { irga })}(f) T_{\text {dsonic }}(f) T_{\mathrm{m}}(f) T_{\mathrm{w}}\left(f_{\mathrm{p}}\right) T_{\mathrm{s}}\left(f_{\mathrm{s}}\right) T_{\mathrm{t}}(f)$

where $T_{\mathrm{r}}(f)$ is digital recursive running mean, $T_{\mathrm{d}}(f)$ is the dynamic frequency response of the sensor (sonic, Li-7500 or ENVI), $T_{\mathrm{m}}(f)$ is the sensor response mismatch, $T_{\mathrm{w}}\left(f_{\mathrm{p}}\right)$ is the scalar path averaging, $T_{\mathrm{s}}\left(f_{\mathrm{s}}\right)$ is the sensor separation loss, and $T_{\mathrm{t}}(f)$ is the frequency attenuation of the gas concentration caused by tubing, which is most significant for a closed-path system. Moncrieff et al. (1997) presented $T_{\mathrm{t}}(f)$ as

$T_{\mathrm{t}}(f)=\exp \left(\frac{-\pi^{2} r_{\mathrm{t}}^{2} L_{\mathrm{t}} f^{2}}{6 D_{\mathrm{s}} U_{\mathrm{t}}}\right)=\exp \left(\frac{-\pi^{2} r_{\mathrm{t}}^{2} \tau f^{2}}{6 D_{\mathrm{s}}}\right)$

where $U_{\mathrm{t}}$ is the air speed in the tubing, $D_{\mathrm{s}}$ is the $\mathrm{O}_{3}$ molecular diffusivity $\left(0.1444 \mathrm{~cm}^{2} \mathrm{~s}^{-1}\right), \tau$ is mean lag time, $L_{\mathrm{t}}$ and $r_{\mathrm{t}}$ are the tube length and radius, respectively. Aubinet et al. (2000) found that $T_{\mathrm{t}}(f)$ calculated in Eq. (11) may overestimate the effects of tubing attenuation and changed the constant from 6 to 12 .

2.3.4.2. In-situ transfer function and empirical method. In this study, we employed the in-situ/analytic combination method as proposed by Ibrom et al. (2007). The basic idea of this method is that the flux loss at high frequencies can be considered as the effect of a low-pass filter. If the non-attenuated flux (for example, sensible heat flux measured by $T_{\mathrm{S}}$ and $w$ ) is intentionally degraded by digital filtering, the total loss can be estimated by the ratio of raw covariance to the filtered eddy covariance. Based on the Monin-Obukhov similarity theory, we can assume that all scalars' co-spectra (with $w$ ) have similarity in the atmospheric boundary-layer, and the correction factor for the spectral loss at high frequency can be estimated as

$\mathrm{CF}=\frac{\overline{w^{\prime} S^{\prime}}}{\overline{w^{\prime} S^{\prime} \mathrm{m}}}=\frac{\bar{w}^{\prime} T_{\mathrm{s}}{ }^{\prime}}{w^{\prime} T_{\mathrm{s}}{ }^{\prime} \mathrm{lp}}$

The subscript lp denotes a low-pass filtered data. One can use a first-order recursive filter, which is sometimes referred to as an infinite impulse response filter. The detailed calculation method of infinite impulse response filter can be found in Ibrom et al. (2007). To reduce the effect of high frequency noise, only "high quality" spectra were used to calculate ensemble spectra in EddyPro ${ }^{\circledR}$ (LICOR, 2013).

Eq. (12) cannot give an accurate CF value when the sensible heat flux is very small. In this present study, the CF was estimated by (Ibrom et al., 2007)

$\mathrm{CF}=\frac{c_{1} u}{c_{2}+f_{c}}+1$

where $c_{1}$ and $c_{2}$ are site-specific parameters determined by turbulence data.

\subsubsection{Other corrections}

Ozone flux loss due to time delay was corrected by the maximum covariance method (Moncrieff et al., 1997). To avoid unrealistic lag times, we set a lower and upper limit of $2.1 \mathrm{~s}$ and $3.5 \mathrm{~s}$, respectively (Li-COR, 2013). Based on the ENVI's measurement principle, the WPL correction (Webb et al., 1980) for an open-path sensor should be applied to the $\mathrm{O}_{3}$ flux measurements (Güsten and Heinrich, 1996; Lamaud et al., 2002; Zahn et al., 2012). However, due to the relative long tubing with small diameter, temperature fluctuation in the cell might be damped considerably (Burba et al., 2012). Hence, the WPL term only considered density variations caused by water vapor.

\section{Results and discussions}

\subsection{The effect of different calibration methods on $F_{o}$}

\subsubsection{Time series changes of ENVI's signal-output, $\mathrm{O}_{3}$} concentration and their ratio

Fig. 1a shows an 8-day (May 5-12, 2012) time series of $30 \mathrm{~min}$ absolute mean $\mathrm{O}_{3}$ concentration (measured by M205) and ENVI's signal-output. During this period, we changed the dye disc 3 times, at 17:00 May 5, 12:00 May 8 and 9:00 May 11, 2012 (indicated by the vertical lines in Fig. 1). The output of the M205 (ppb) has been converted into $\mathrm{O}_{3}$ concentration $\left(\mu \mathrm{g} \mathrm{m}^{-3}\right)$. Overall, the ENVI's signal-output $(X)$ followed the absolute concentrations fairly well, indicating that the ENVI signal-output had positive correlation with the ambient $\mathrm{O}_{3}$ concentration. The linear regression equation of the two concentrations in 8 days $(n=428)$ was $X=2.66 \rho 0-15.1$, and $R^{2}=0.602$.

The ratio of ENVI's signal-output to absolute $\mathrm{O}_{3}$ concentration can be considered as the ENVI's sensitivity, and its temporal variation is a measure of the temporal stability of ENVI's signal-output (Fig. 1b). In the experiment, the ratio showed a day-by-day decreasing trend for each disc period, and also showed a clear diurnal variation, indicating that the ratio could be influenced by some environmental variables. The long-term (1-3 days) variation of the ratio was mainly affected by the consumption of ozone-sensitive dye on the disc. Particularly, during the first few hours after disc change, the sensitivity is unstable and the data are usually discarded because of containing spurious values (Ermel et al., 2013; Muller et al., 2010). Further, the ratio was strongly affected by environmental factors, especially the air humidity (Güsten and Heinrich, 1996), which makes the ratio become unstable.

Fig. 2 shows the relationship between the ratio and relative humidity (RH). Although there were negative correlations between them, the scatter relationship shows that the ratio was greatly affected by other factors, such as the consumption of ozonesensitive dye in disc. Furthermore, the results of Fig. 1 b indicate that the ratio was not steadily decreasing in the field. This complicated variation will influence the unit conversion from voltage to absolute $\mathrm{O}_{3}$ concentration, which could affect the $\mathrm{O}_{3}$ flux estimation. 

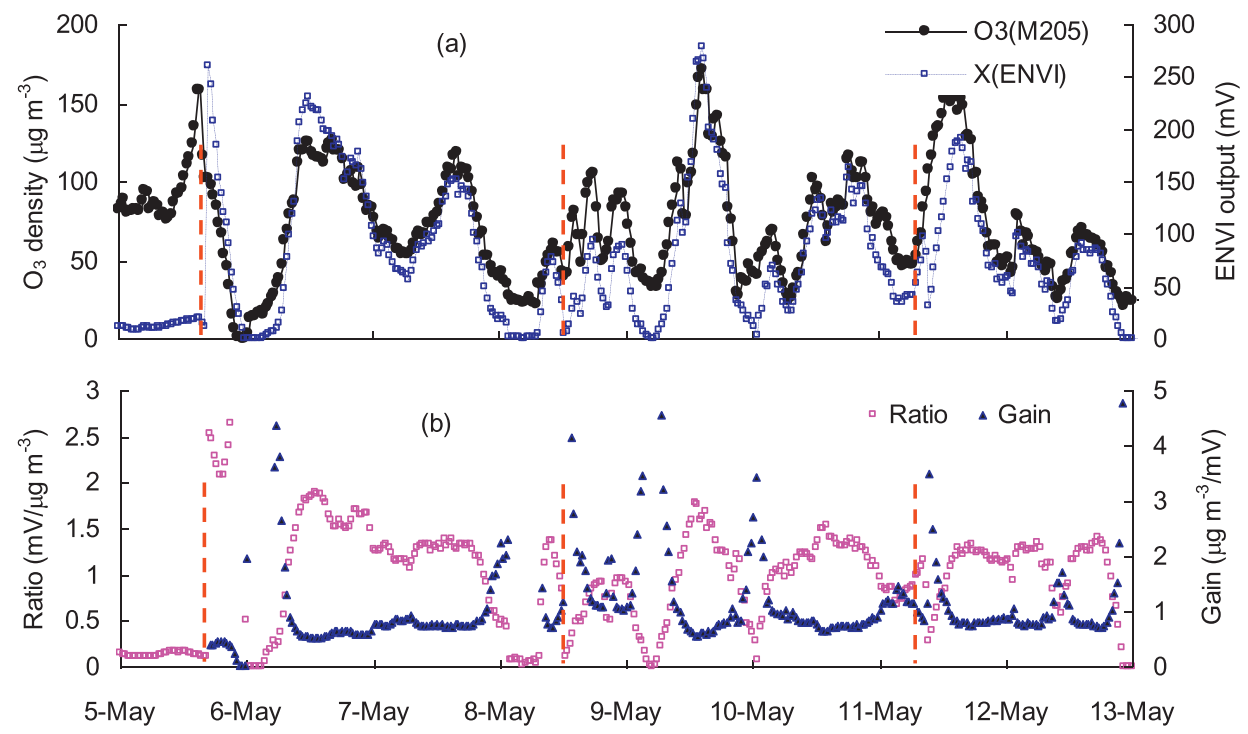

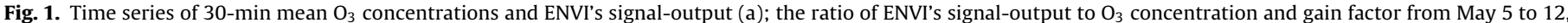
2012 (b). Vertical dash lines indicate the time of changing the dye disc for the ENVI $\mathrm{O}_{3}$ analyzer.

\subsubsection{Stability analysis of the zero offset and gain factor}

Fig. 3 shows plots of $30 \mathrm{~min}$ mean ENVI's signal-output $(X)$ versus $\mathrm{O}_{3}$ absolute concentration during 4 typical disc periods. The intercepts obtained from each individual regression equations are the offsets of ENVI's signal-output during each disc period. Clearly, the regression lines did not have zero offsets, indicating that most of the time $X$ was not directly proportional to the absolute concentration. Moreover, there was a large variation of offsets during different disc periods. According to Eq. (4), we calculated the mean offset of each disc period during the entire observational period. Corresponding offsets ranged from $-48.2 \mathrm{mV}$ to $19.8 \mathrm{mV}$. The overall mean of all offsets was $-7.6 \mathrm{mV}$ for the entire experiment.

As the offset was calculated by the extrapolation based on the linear regression of $\mathrm{O}_{3}$ concentration and $X$, it could be affected by the choice of statistical data of different period and number. This implies that the sensitivity is fixed during the selected periods. Muller et al. (2010) suggested that one offset can only be used for one disc measurement period (3-4 days in this study). This is acceptable for some disc periods. For example, for the periods shown in Fig. $3 \mathrm{c}$ and $\mathrm{d}$, there was a very good relationship between ENVI's signal-output and $\mathrm{O}_{3}$ concentration. While during the disc period presented in Fig. 3a, data points were not narrowly dis-

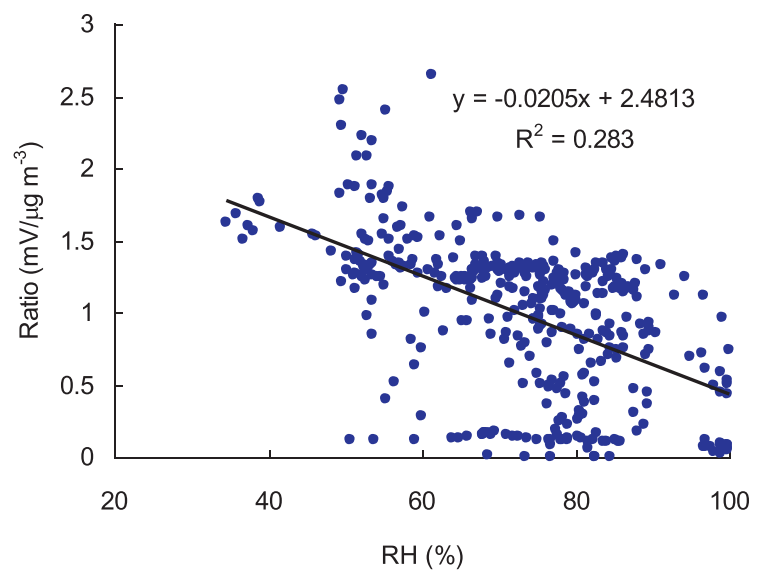

Fig. 2. Relationship between the ratios of ENVI's signal-output to $\mathrm{O}_{3}$ concentration and relative humidity (RH) from May 5 to 12, 2012. tributed around the regression line, and the offset could be affected by the data choice. It is worth noting that the extrapolated offsets were not equal to the real offsets at zero $\mathrm{O}_{3}$ concentration. Most extrapolated offsets were negative, as shown above, and the real ENVI"s signal-output were always positive when $\mathrm{O}_{3}$ concentration was close to zero. Under the conditions when ambient $\mathrm{O}_{3}$ concentrations were less than $1 \mathrm{ppb}$, the ENVI's signal-output $X$ was $7.5 \pm 9.6 \mathrm{mV}$ (mean \pm std).

From Fig. 1b, we can see that there were large variations of the gain factor between two adjacent 30 min periods. Neglecting the changes of gain factor within a $30 \mathrm{~min}$ period may result in inaccurate estimations of $\mathrm{O}_{3}$ concentration, from this perspective, the period for calculating the gain factor should be shortened. However, the gain factor could be affected by analyzer's noise if the averaging time is too short. Hence, it is necessary to determine an optimal averaging time.

The AW variance is often used to investigate the stability of an instrument gain factor (Werle et al., 1993; Bowling et al., 2003; Griffis et al., 2008). Fig. 4a shows the variation of the AW variance of the gain factor with averaging time. With the increase of averaging time from $1 \mathrm{~s}$ to about $100 \mathrm{~s}$, the AW variance shows almost a linear decrease in the log-log coordinate, indicating that the effect of white noise on the gain factor was decreasing. However, when averaging time further increased from about $200 \mathrm{~s}$, the value of the AW variance was increasing again. This was resulting from the long-term drift of the gain factor.

The AW variance provides a measure for determining the optimal averaging-time, at which the AW variance is the smallest. However, the determination of averaging-time needs comprehensive consideration in practice. For example, Bowling et al. (2003) studied the stability of a tunable diode laser absorption spectrometer for the carbon isotope measurements and determined the averaging-time as $2 \mathrm{~min}$, in spite of that the AW variance started to increase from an averaging-time of $40 \mathrm{~s}$. Similarly, although the lowest AW variance occurred at about $100 \mathrm{~s}$, we decided to use $180 \mathrm{~s}$ ( $3 \mathrm{~min}$ ) as the optimal averaging time in this present study. It is worth noting that the eddy covariance averaging time was still 30 min rather than $3 \mathrm{~min}$, and only $10 \mathrm{~Hz} X$ was calibrated by Eq. (6) for each $3 \mathrm{~min}$ when using the RVM. The calibration coefficient (gain factor) varied for different 3-min interval. This will not result in the flux loss from low frequency contribution to total flux. 

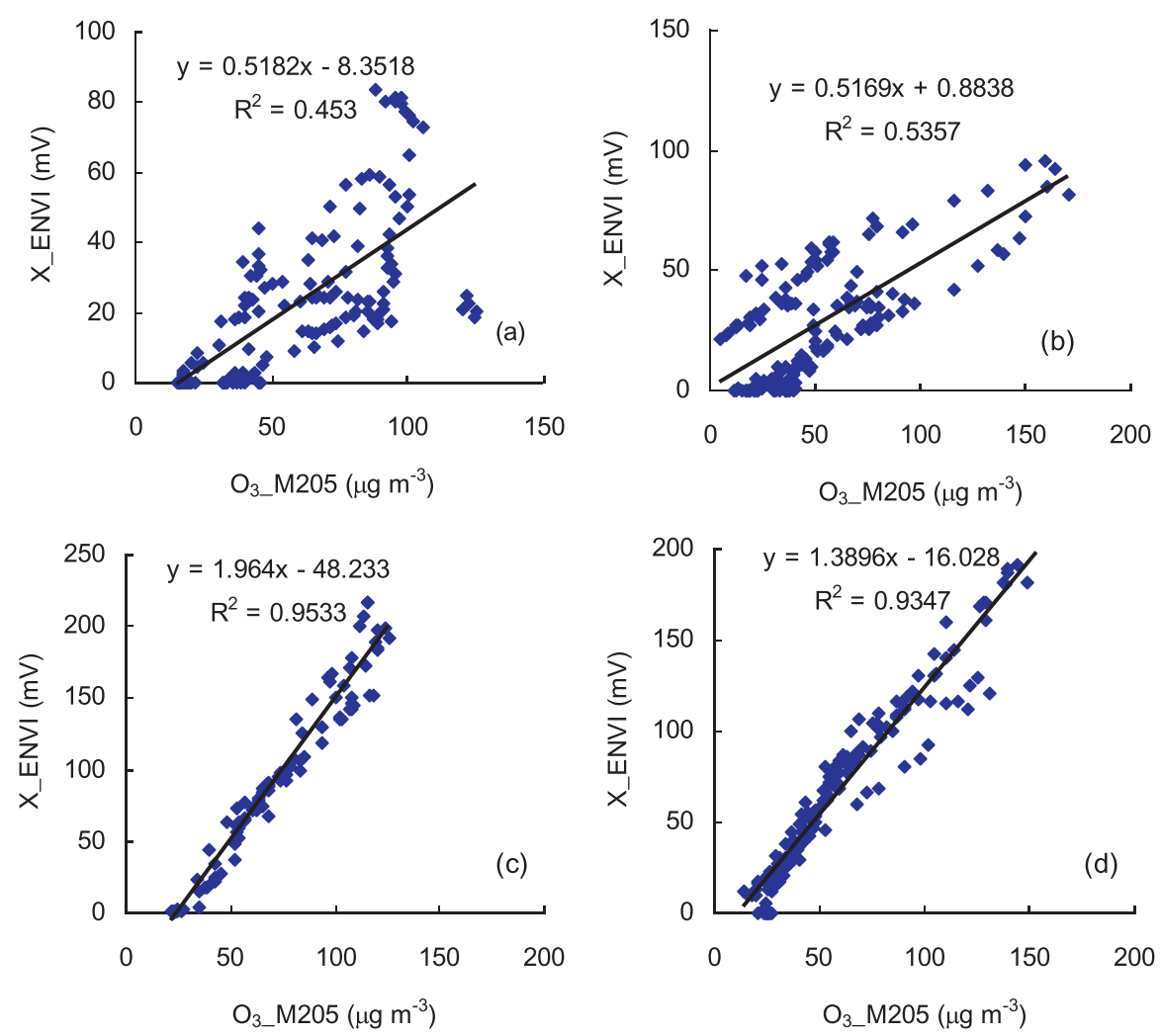

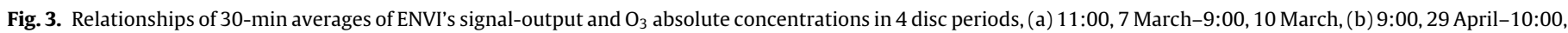
2 May, (c) 10:00, 6 May-15:00, 9 May, and (d) 11:00, 11 May-9:00, 15 May, 2012.
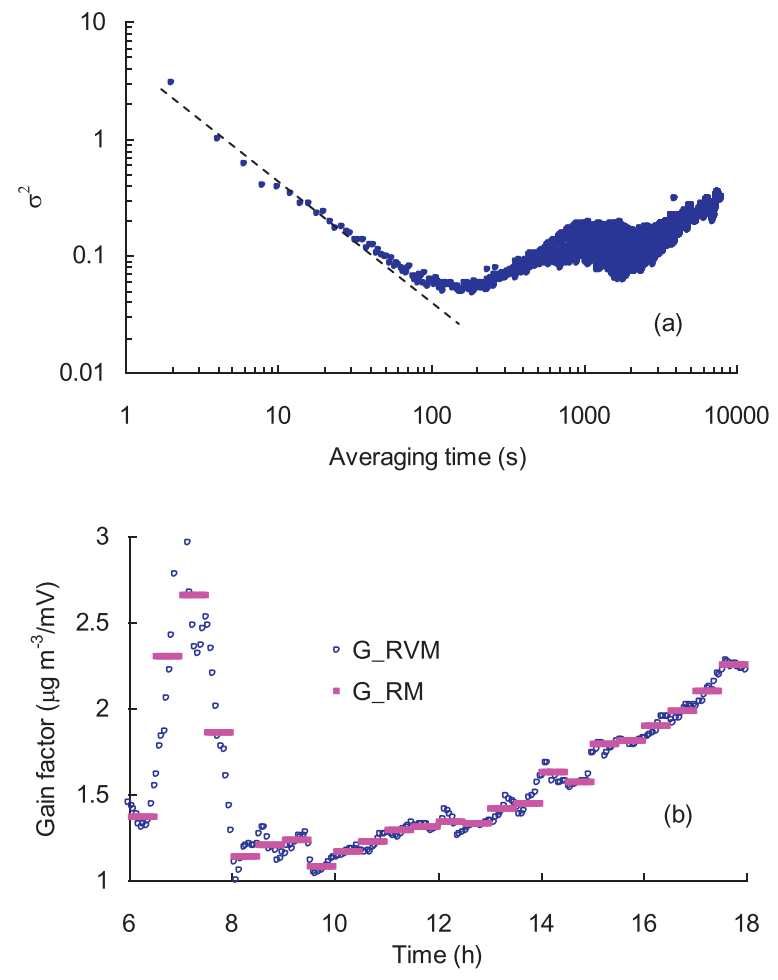

Fig. 4. Allan-Werle variance analysis and gain factor comparison. (a) Variation of the AW variance of ENVI's gain factor with averaging time. The slope shows the effect of white noise. (b) Comparison of gain factors by ratio method and ratio variation methods. The data was from 6:00-18:00, 14 May, 2012.
Different calibration methods/models can result in different gain factors, consequently affecting the final $\mathrm{O}_{3}$ flux. Fig. $4 \mathrm{~b}$ shows a diurnal variation of gain factors ( 3 min mean) with the ratio method and the ratio variation method, respectively. The gain factor of the ratio variation method ( $\left.G_{-\mathrm{RVM}}\right)$ may reflect the short time (3 min) variation. The difference of the two gain factors was clear when the gain factor was rapidly changing, which was usually occurring in the morning (Fig. 1b).

\subsubsection{Comparison of $F_{o}$ calculated by different calibration methods}

Fig. 5 shows the comparisons of daytime $\mathrm{O}_{3}$ fluxes calculated by ratio method ( $\left.F_{\text {O_RM }}\right)$ and by ratio offset method $\left(F_{\text {o_ROM }}\right)$ or by ratio variation method $\left(F_{O_{-} \text {RVM }}\right)$. On average, $F_{O_{-} \text {ROM }}$ and $F_{O_{-} \text {RVM }}$ are about $9 \%$ and $7 \%$ lower than $F_{O_{-} R M}$, respectively. The RM and RVM have the same basic assumptions, and the RVM accounts for the variation of gain factor within a $30 \mathrm{~min}$ period. The estimates of $\mathrm{O}_{3}$ concentration by RVM followed more closely to the changes of $\mathrm{O}_{3}$ concentration. The differences of $\mathrm{O}_{3}$ fluxes calculated by RVM and RM may suggest that the commonly used ratio method might overestimate the $\mathrm{O}_{3}$ flux.

Muller et al. (2010) also presented another method, the socalled "disc calibration method, DCM". Here, the final $F_{0}$ is equal to the covariance of $w$ and $X$ multiplied by a constant for each disc period. The constant is obtained by the linear regression of $15 \mathrm{~min}$ averaged absolute $\mathrm{O}_{3}$ concentrations against the fast-response analyzer's signal-output. This method implies that gain factor is a constant during one disc period. However, our data (Fig. 1b) showed this is not the case. Further, we tried to evaluate ozone concentration using the linear regression method, which was based on the assumption that 5 min mean of $\mathrm{O}_{3}$ concentration is linearly changing with 5 min mean of $X$ over a 30 min period. However, the regression coefficients strongly depended on the data quality and 

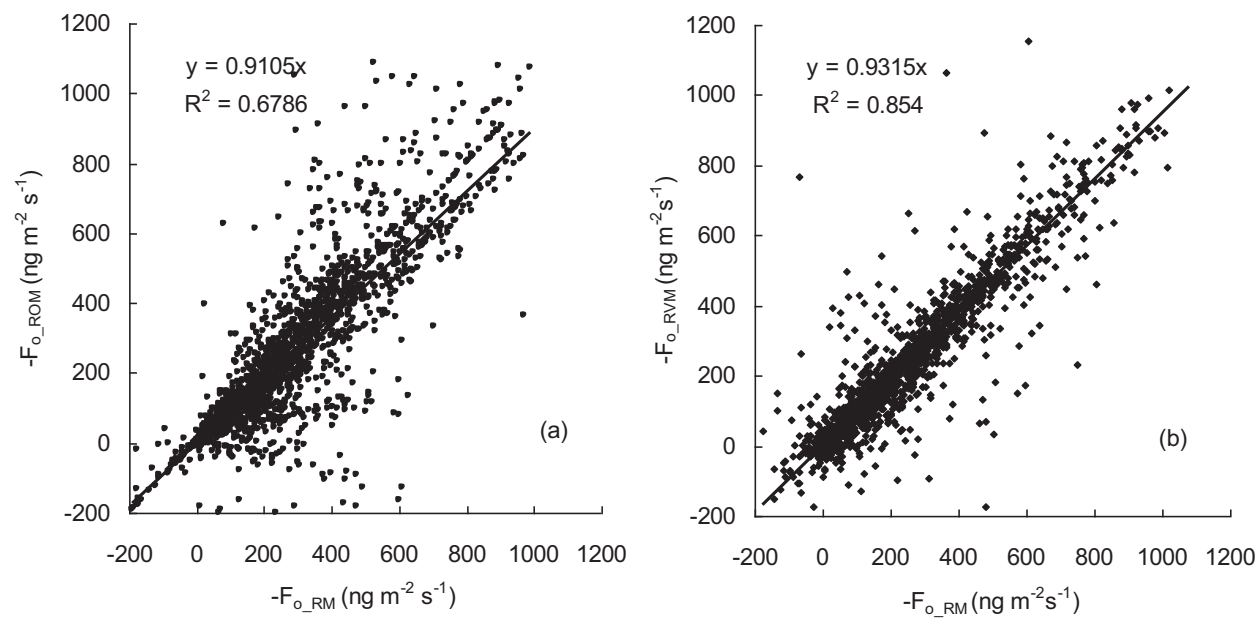

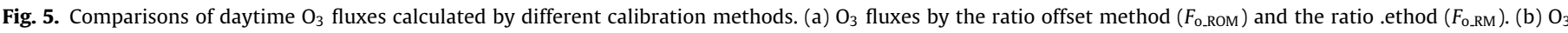
fluxes by the ratio variation method $\left(F_{\mathrm{O}_{-} \mathrm{RVM}}\right)$ and $F_{\mathrm{O}_{-} \mathrm{RM}}$
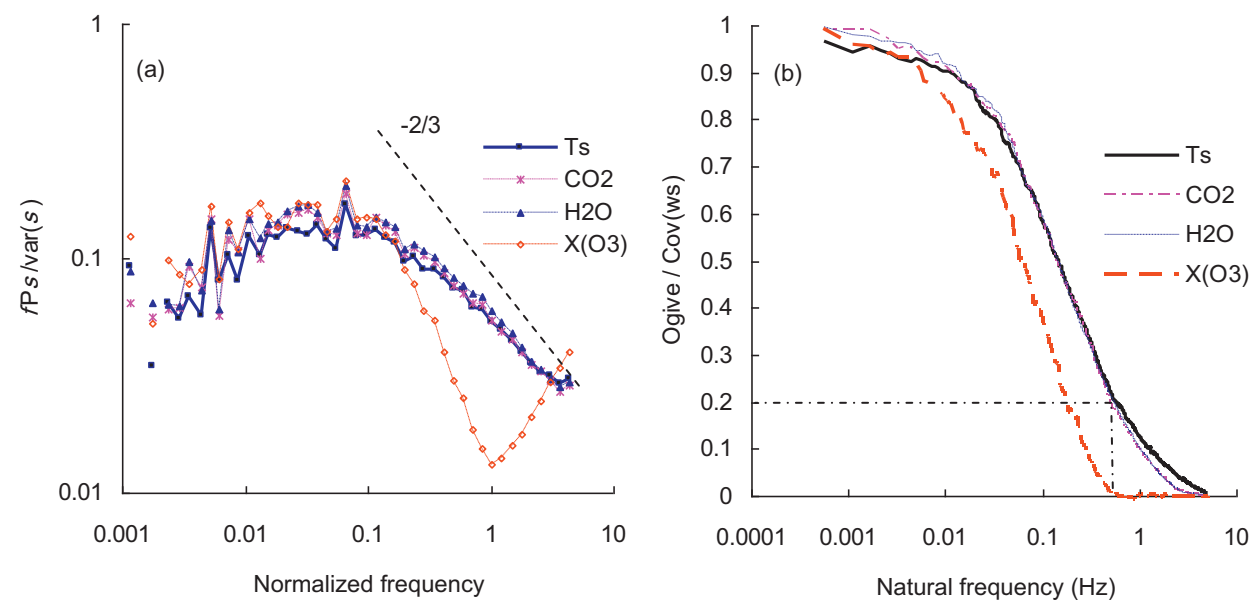

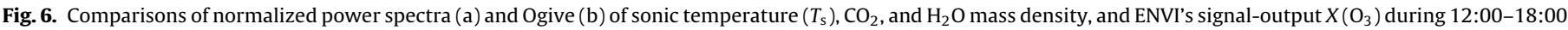
14 May 2012. The dash vertical line is at $0.5 \mathrm{~Hz}$ and all Ogive curves were normalized by their covariance.

instruments' precision. Consequently, the $\mathrm{O}_{3}$ flux shows a large and unstable variation (data not shown).

The different calibration methods illustrate the differences in the basic assumptions on determining gain factor and offset for a disc period (Table 1 ). Both the ratio offset method and the ratio variation method improved the commonly used ratio method by considering the effect of offset and gain factor variation on $\mathrm{O}_{3}$ flux estimation. As the offset was extrapolated by linear regression methods, 30 min mean $\mathrm{O}_{3}$ flux can not be individually calculated by using the ratio offset method, and the offset was strongly influenced by the data quality over a disc periods. In contrast, the 30 min mean $\mathrm{O}_{3}$ flux can be individually calculated by using the ratio variation method.

\subsection{Spectral analysis}

Fig. 6a shows power spectra of 4 scalars during 12:00-18:00, 14 May, 2012, when the weather was fair and turbulence was strong. Friction velocity $u^{*}$ varied between $0.12 \mathrm{~m} \mathrm{~s}^{-1}$ and $0.35 \mathrm{~m} \mathrm{~s}^{-1}$ and atmospheric stability $(z-d) / L$ ranged from -0.01 to -0.08 ( $z$ : height of measurement, $d$ : zero-plane displacement, $L$ : Monin-Obukhov length). To compare the relative changes, all individual spectra were normalized by their variance $\sigma^{2}$. On the abscissa, the spectra were averaged at matching normalized fre- quencies $n=f(z-d) / u$, where $u$ is the mean wind speed. The spectra of sonic temperature $\left(T_{\mathrm{s}}\right), \mathrm{CO}_{2}$ and $\mathrm{H}_{2} \mathrm{O}$ density are also presented for comparison. There were some differences in the performance of the scalar $X\left(\mathrm{O}_{3}\right)$ from the other three scalars $\left(T_{\mathrm{s}}, \mathrm{CO}_{2}\right.$ and $\left.\mathrm{H}_{2} \mathrm{O}\right)$ at high frequencies. Two undesired effects, high frequency noise and attenuation are obvious for the ENVI $\mathrm{O}_{3}$ analyzer in the high frequency range.

Theoretically, the high-frequency behaviour of all scalars should be consistent with local isotropy, and in the inertial sub-range the power spectra should fall as a $-2 / 3$ power law when $n \mathrm{P}(n)$ is plotted against $n$ in log-log scale (Kaimal et al., 1972). The spectra of the three scalars $T_{\mathrm{s}}, \mathrm{CO}_{2}$, and $\mathrm{H}_{2} \mathrm{O}$ in the inertial sub-range follow the $-2 / 3$ slope line, indicating both the sonic anemometer and $\mathrm{CO}_{2} / \mathrm{H}_{2} \mathrm{O}$ gas analyzer had a reasonable high-frequency response. However, for ENVI's signal-output $X\left(\mathrm{O}_{3}\right)$, change of spectral density in the log-log plot shows that there was distinct white noise at frequencies higher than 1, which was most likely due to the ENVI's electronic noise. Besides noise, one particular concern is the socalled tubing attenuation which is obviously manifested for $n>0.3$. This is a well known and common issue for almost all closed-path eddy covariance systems (Leuning and Moncrieff, 1990; Leuning and King, 1992). The attenuation of $\mathrm{O}_{3}$ fluctuation is determined by the transport time and the flow regime (laminar or turbulent) in the inlet tube (Zahn et al., 2012). The low flow rate $\left(0.81 \mathrm{~min}^{-1}\right)$ may 

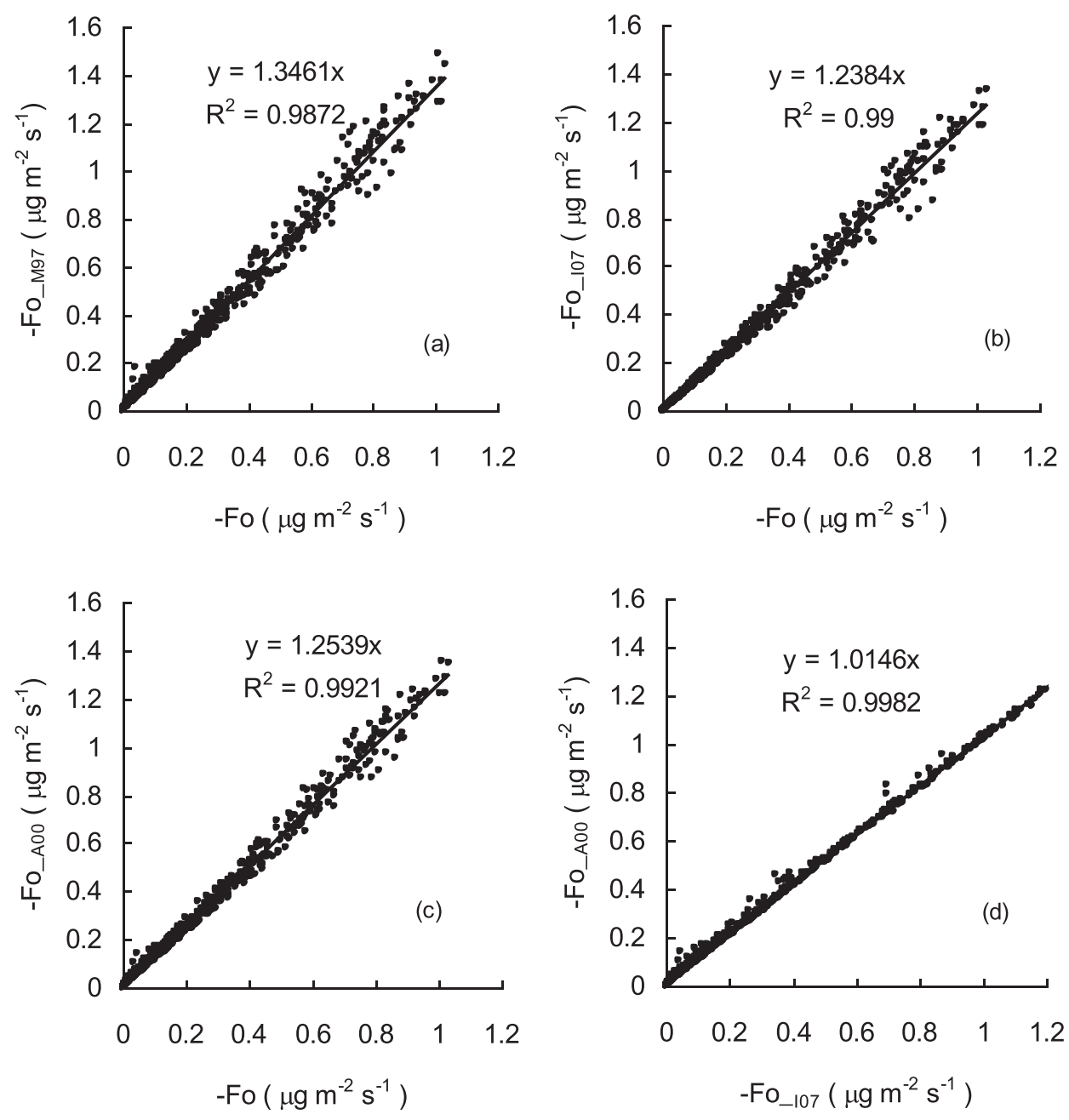

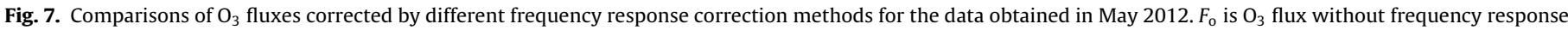
correction. $F_{\mathrm{O}_{-} \mathrm{M} 97}, F_{\mathrm{O}-107}$ and $F_{\mathrm{O} \_\mathrm{A} 00}$ are the fluxes with frequency response corrections of Moncrieff et al. (1997), Ibrom et al. (2007) and Aubinet et al. (2000), respectively.

undermine eddy covariance measurements of ozone, and a higher flow rate (3.5-4.5 $1 \mathrm{~min}^{-1}$ ) could alter the flow regime, resulting in the decrease of $\mathrm{O}_{3}$ concentration fluctuation attenuation and flux loss at high frequencies (Appendix A). Moreover, shortening the tube length (if possible) can reduce the transport time in the field measurement.

Fig. $6 \mathrm{~b}$ shows the mean normalized Ogive curve for 4 scalars with vertical wind speed $(w)$ during 12:00-18:00, 14 May, 2012. Compared with the Ogive of $T_{\mathrm{s}}$, the Ogive curves of $\mathrm{CO}_{2}$ and $\mathrm{H}_{2} \mathrm{O}$ suggest that the performance of the $\mathrm{CO}_{2} / \mathrm{H}_{2} \mathrm{O}$ gas analyzer was excellent. However, the ENVI $\mathrm{O}_{3}$ analyzer performed very differently. In the high frequency range (roughly for $f>0.5 \mathrm{~Hz}$ ), the mean Ogive curve of $X\left(\mathrm{O}_{3}\right)$ is approaching zero, indicating that high frequency contribution to the total $F_{\mathrm{O}}$ was not significant and the high frequency noise is not correlated with $w$. This is consistent with published results (Leuning and King, 1992; Rummel et al., 2002). Even so, the noise can cause run-to-run random errors of the $\mathrm{O}_{3}$ flux, and can also disturb the derivation of the transfer function, as the low-pass filtering effect and noise occur in the same spectral ranges (Ibrom et al., 2007).

For lower than $0.5 \mathrm{~Hz}$, the Ogive of $X\left(\mathrm{O}_{3}\right)$ increased rapidly and similar to the other scalars. This suggests that the ENVI $\mathrm{O}_{3}$ analyzer has a good performance at these frequencies. On average, the contribution of frequencies higher than $0.5 \mathrm{~Hz}$ to the total flux was about $20 \%$ for $T_{\mathrm{s}}, \mathrm{CO}_{2}$ and $\mathrm{H}_{2} \mathrm{O}$, indicating that there was about $20 \%$ high frequency loss for $\mathrm{O}_{3}$ flux according to the Monin-Obukhov similarity theory. The ratio (20\%) will be helpful to judge which frequency response correction is the most appropriate.

Table 1

Comparison of the basic assumptions on determining gain factor and zero offset with different calibration methods.

\begin{tabular}{|c|c|c|c|c|}
\hline \multirow[t]{2}{*}{ Method } & \multicolumn{2}{|l|}{ Gain factor } & \multicolumn{2}{|l|}{ Offset } \\
\hline & Within a $30-\mathrm{min}$ & Different 30-min & Within a $30-$ min & Different 30-min \\
\hline Ratio method & Fixed & Variational & 0 & 0 \\
\hline Ratio offset method & Fixed & Variational & Fixed & Fixed \\
\hline Ratio variation method & Variational & Variational & 0 & 0 \\
\hline Disc calibration method & Fixed & Fixed & Fixed & Fixed \\
\hline Linear regression method & Fixed & Variational & Fixed & Variational \\
\hline
\end{tabular}




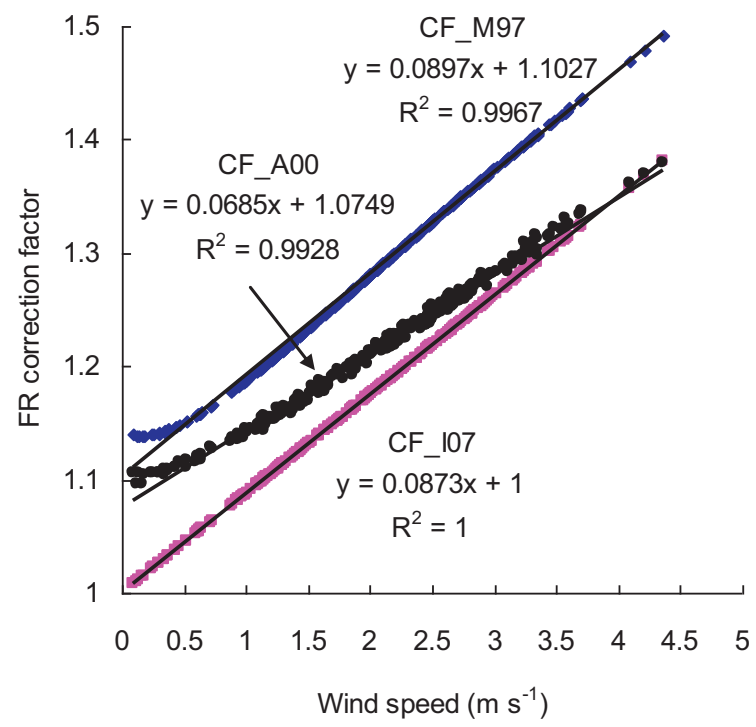

Fig. 8. Relationships between wind speed and frequency correction factors of three methods, Moncrieff et al. (1997), Ibrom et al. (2007) and Aubinet et al. (2000), for the daytime $\mathrm{O}_{3}$ flux data.

\subsection{The effect of different frequency response (FR) corrections on $F_{0}$}

\subsubsection{Comparison of $F_{o}$ corrected by different FR correction methods}

One purpose of spectral analysis is to find a suitable frequency response correction method. Fig. $7 \mathrm{a}$ and $\mathrm{b}$ compares $F_{\mathrm{o}}$ before and after spectral corrections. Because of high frequency noise, we just used spectral data with a frequency slower than $1 \mathrm{~Hz}$ for fitting the in-situ transfer function as described by Ibrom et al. (2007). Compared to uncorrected $F_{0}$, the corrected fluxes by Moncrieff et al. (1997) $\left(F_{\text {O_M97 }}\right)$ and by Ibrom et al. $(2007)\left(F_{\text {O_I07 }}\right)$, are on average increased by $34.6 \%$ and $23.8 \%$, respectively.

Generally, spectral correction factors range between 1.04 and 1.25 for $\mathrm{CO}_{2}$ flux measured with closed-path systems (Baldocchi, 2003). In addition, according to our Ogive analysis above, high frequency $\mathrm{CF}$ should be close to 1.25 [1/(1-0.2)]. Moreover, compared with uncorrected $F_{0}$, the $\mathrm{O}_{3}$ flux corrected by Aubinet et al. (2000) method $\left(F_{\text {O_A A00 }}\right)$ is on average $25.4 \%$ higher (Fig $7 \mathrm{c}$ ). However, $F_{\mathrm{O}_{-} \mathrm{A} 00}$ is in excellent agreement with $\mathrm{F}_{\mathrm{O}-\mathrm{I} 07}$; both $\mathrm{O}_{3}$ fluxes differ only about 1\% (Fig 7d). Obviously, the mean correction factor of the Moncrieff et al. (1997) method ( $C F_{-M 97}$ ) seems to be out of range. Therefore, the Moncrieff et al. (1997) method might overestimate the effect of flux loss caused by tubing concentration attenuation (Aubinet et al., 2000).

\subsubsection{Relationship between wind speed and different FR correction factors}

The differences among three high frequency response correction factor (CF) values were considered in the light of their relationships with daytime wind speed (Fig. 8). For all methods, there were good linear relationships when wind speeds were higher than $0.5 \mathrm{~m} \mathrm{~s}^{-1}$. The slopes of correction factor lines calculated according to Moncrieff et al. (1997) (CF_M97) and Ibrom et al. (2007) (CF_107) were nearly equal, but there is an offset of 0.1 between $\mathrm{CF}_{\mathrm{M} 97}$ and $\mathrm{CF}_{\text {I07 }}$. The slope of $\mathrm{CF}_{\mathrm{A00}}$, calculated based on Aubinet et al. (2000), is less than those of $\mathrm{CF}_{\mathrm{M} 97}$ and $\mathrm{CF}_{\mathrm{I}}$.7. At low wind speed conditions $\left(u<0.5 \mathrm{~m} \mathrm{~s}^{-1}\right)$, there were clear variations in $\mathrm{CF}_{\text {. }} \mathrm{CF}_{-\mathrm{A} 00}$ and $\mathrm{CF}_{\mathrm{M} 97}$ revealed offset constants of 1.1 and 1.15 , respectively, while $\mathrm{CF}_{\text {I07 }}$ varied linearly with wind speed.
It seems that no individual frequency response correction method for the $\mathrm{O}_{3}$ flux can be applied for all conditions. However, the Aubinet et al. (2000) method considers the effect of frequency response correction for weak and strong wind speeds. Consequently, it has wider applicability.

\section{Conclusions}

In this study, we evaluated the performance of a fast-response $\mathrm{O}_{3}$ analyzer and the effect of different correction methods on eddy covariance $\mathrm{O}_{3}$ flux calculation. Some conclusions can be summarized as following:

(1) Since the fast-response analyzer's sensitivity or gain factor is affected by both the consumption of the chemiluminescence dye and the atmospheric environment conditions particularly the air humidity, there is no way to avoid in-situ calibration. Compared to the $\mathrm{O}_{3}$ flux obtained with the commonly used ratio method, the $\mathrm{O}_{3}$ fluxes estimated with ratio offset method and ratio variation method were decreased by about $9 \%$ and $7 \%$ on average. In the ratio offset method, the offset was extrapolated by linear regression method, and there was a larger uncertainty. In the ratio variation method, the optimal averaging time (3 min) was determined by the AW variance method.

(2) Based on spectral analysis, both high-frequency noise and tubing attenuation occured at high frequency ranges. The noise did not result in systematic errors, but it could result in random errors in $\mathrm{O}_{3}$ flux. Due to the low flow rate, tubing attenuation can lead to about $20 \%$ loss of $\mathrm{O}_{3}$ flux.

(3) The $\mathrm{O}_{3}$ fluxes corrected by the original analytic method of Moncrieff et al. (1997) were larger than those by the methods described by Ibrom et al. (2007) and Aubinet et al. (2000). Based on the results of spectral analysis, we infer that the original analytic method overestimated the effect of $\mathrm{O}_{3}$ concentration fluctuation attenuation on $\mathrm{F}_{\mathrm{O}} . \mathrm{O}_{3}$ flux corrected by Aubinet et al. (2000) had a very good agreement with that by Ibrom et al. (2007).

\section{Acknowledgements}

The authors thank two anonymous reviewers and our Associate Editor, Dr. Timothy J. Griffis for their constructive comments and suggestions. This work was financially supported by the National Natural Science Foundation of China (No. 31070400), National Basic Research Program of China (No. 2010CB833501), the Innovation Project of the Institute of Geographic Sciences and Natural Resources Research, Chinese Academy of Science (No. 201003001), and the Max Planck Society (Germany). We would also like to thank Dr. Jiahong Li at LI-COR Biosciences for helping us with the use of EddyPro $^{\circledR}$ software.

\section{Appendix A. The spectral performances of ozone analyzers at higher flow rate.}

The spectral performances of ozone analyzers at higher flow rate.

To validate the effect of flow rate on ozone concentration fluctuation, we conducted a side-by-side comparison experiment from July 19 to August 12, 2013 over grass and low vegetation at the airfield Mainz-Finthen (Germany). In the experiment, four fastresponse $\mathrm{O}_{3}$ analyzers of the same type (named as FXM1, FXM2, FXM4 and ITR1, the analyzer used in Yucheng experiment was exclusive) with higher flow rate were used. The experiment conditions were similar to the Yucheng experiment. The measurement 
Table A.1

Characteristics of the four fast ozone instruments.

\begin{tabular}{lll}
\hline Ozone analyzer & Flow rate $\left(\mathrm{min}^{-1}\right)$ & Mean velocity $\left(\mathrm{m} \mathrm{s}^{-1}\right)$ \\
\hline FXM1 & 3.45 & 1.29 \\
FXM2 & 4.51 & 1.69 \\
FXM4 & 4.4 & 1.65 \\
ITR1 & 4.34 & 1.63 \\
\hline
\end{tabular}

height was $2.8 \mathrm{~m}$, and the tube length of the four systems was $3 \mathrm{~m}$. The mean flow rate and velocity can be found in Table A.1.

Fig. A.1 shows the averaged power spectra of four ozone analyzers and temperature, which were normalized by their respective variance. The theoretic slope in the inertial subrange is also given. The spectral densities are plotted against the normalized frequency $n=f z / u$. Individual spectra are determined from $30 \mathrm{~min}$ time series. All spectral values were averaged to bins, which are equidistant on the logarithmic scale. Clearly, the temperature spectrum agrees well with the theoretic $n^{-5 / 3}$ slope in the inertial subrange. The power spectra of the analyzers FXM2, FXM4 and ITR1 agree well with the temperature spectrum up to a normalized frequency of about 0.4. For higher frequencies, the power spectral densities of the ozone measurement decrease less and show constant values above a frequency of about 2 . Due to the averaging process, the spectral densities decrease again with frequency for normalized frequencies higher than about 5 . The power spectrum of sensor FXM1 is in agreement to the shape of the power spectra of the other sensors up to a frequency of 0.1 , while it displays constant values for frequencies higher than 0.9 in contrast to a frequency of 2 for the other sensors. The different behaviour is attributed to the characteristics of the ozone sensors, as FXM1 has a relatively lower flow rate than the other sensors (see Table A.1). Besides the ozone sensor itself, the sensitivity of the chemical disc inside the analyzer influences the lower limit of the frequencies affected by noise. Discs with a weak sensitivity increase the contribution of noise to the variance.

Compared to the severe attenuation of power spectra of ozone signal-output above a normalized frequency of about 0.2 in Yucheng (Fig. 6a), the similar performances of power spectral of four ozone analyzers were not appeared. However, the noise was visible in the power spectra of the side-by-side experiment at lower normalized frequencies due to the higher sampling frequency of $50 \mathrm{~Hz}$.

Fig. A.2 shows averaged cospectra between vertical wind speed $(w)$ and temperature as well as ozone signals of the four analyz-

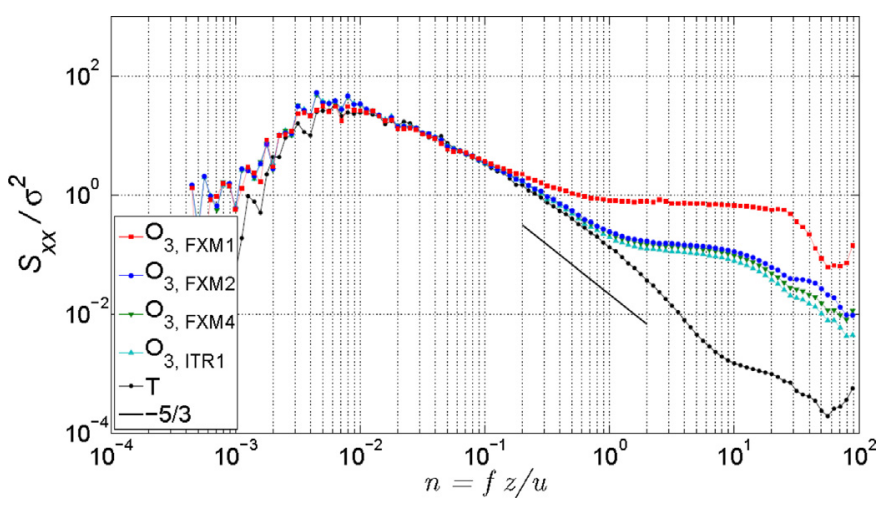

Fig. A.1. 30-Min averaged power spectral densities of temperature $(T)$ and four $\mathrm{O}_{3}$ analyzers (FXM1, FXM2, FXM4 and ITR1) signal-output for the side-by-side experiment over grass at the airfield Mainz-Finthen (Germany). The spectra were normalized by the variance of the scalar $x$ (either $T$ or $\mathrm{O}_{3}$ ). The data of 77 spectra was averaged. The measurement height was $2.8 \mathrm{~m}$. The straight solid line gives the theoretical slope of $-5 / 3$.

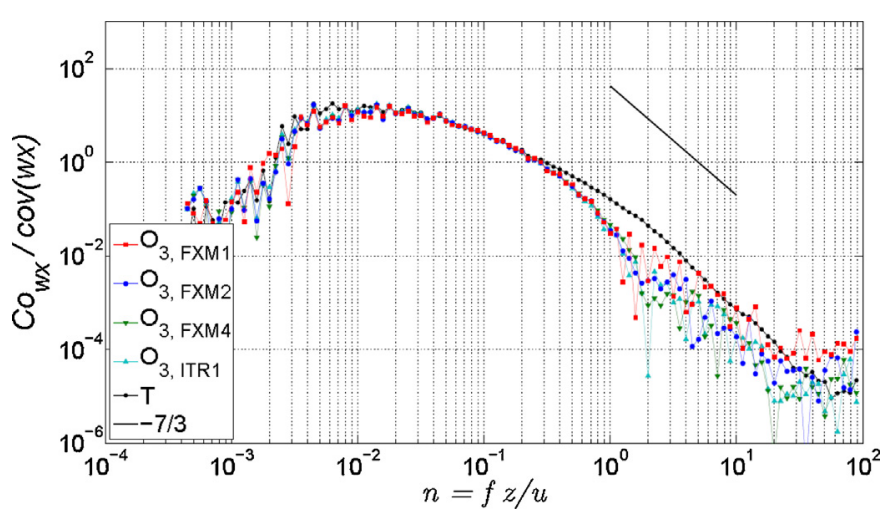

Fig. A.2. 30-min averaged cospectral densities of vertical velocity $(w)$ and temperature $(T)$ as well as four $\mathrm{O}_{3}$ analyzers signal-output for the side-by-side experiment. The cospectra were normalized by the respective covariance. The data of 77 cospectra was averaged. The straight solid line gives the theoretical slope of $-7 / 3$.

ers, which were normalized by their respective covariance with $w$. The theoretic slope in the inertial subrange is given. Similar to the power spectrum of the temperature, the sensible heat flux cospectrum is in good agreement with the theoretic shape. The cospectra of the four ozone analyzers (FXM1, FXM2, FXM4 and ITR1) agree well with the sensible heat flux cospectrum for frequencies up to 0.2 , while the decrease is steeper for frequencies between 0.2 and 2 , which is due to the attenuation of fluctuations during the transport through the tubing with laminar tube flow as well as the effect of sensor separation. For frequencies higher than about 2, the cospectral densities of the ozone fluxes decrease less than those of the sensible heat flux. This agrees with the frequency range at which noise is visible in the power spectra in Fig. A.1, indicating that the noise is not completely uncorrelated to the measurement of vertical wind speed fluctuations.

Overall, the sampling tube in the closed-path system acts as a high-frequency filter. Fig. A. 3 shows the relation between the frequency response correction factor for tube attenuation and the horizontal wind speed for laminar as well as turbulent flow in the tube under unstable conditions. The correction factors are determined using the cospectra parameterized after Kaimal et al. (1972) and the theoretic transfer functions for tube attenuation after Lenschow and Raupach (1991). For the case of turbulent tube flow ( $R e \sim 2300$; Lenschow and Raupach, 1991), a reduced tube radius is assumed. Under laminar flow conditions in the tube, the fluxes of the sensor with the smallest flow rate need the largest correc-

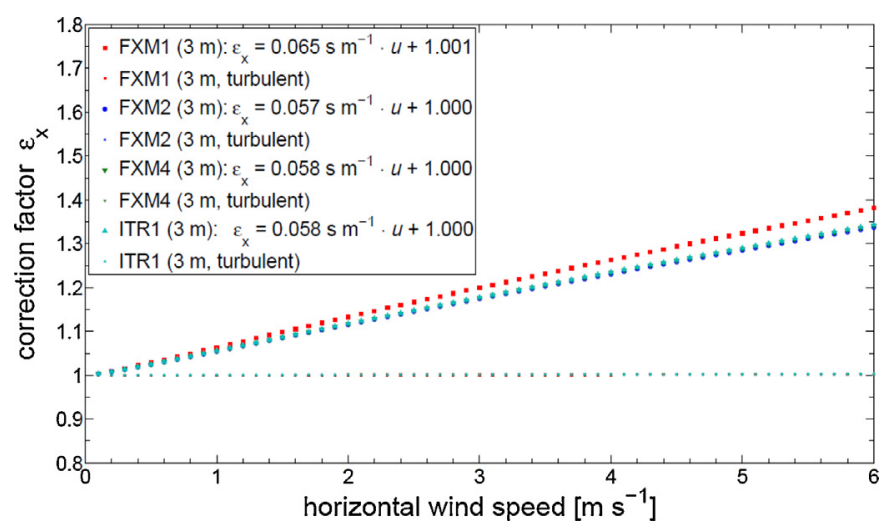

Fig. A.3. Relation between the correction factor and the horizontal wind speed for the sensor systems of the side-by-side experiment. Correction factors are given for laminar as well as turbulent tube flow. Linear regressions for the laminar case are given in the figure. 
tions. Turbulent flow conditions result in a negligible correction. To reduce the effect of tubing on the ozone flux loss at high frequencies in future experiments, one should use a shorter length and a smaller radius of sampling tube as possible. Furthermore, increasing volumetric flow rate can significantly improve the frequency response.

\section{References}

Allan, D.W., 1966. Statistics of atomic frequency standards. Proc. IEEE 54, 221-231.

Aubinet, M., Grelle, A., Ibrom, A., Rannik, U., Moncrieff, J., Foken, T., Kowalski, P., Martin, P., Berbigier, P., Bernhofer, C., Clement, R., Elbers, J., Granier, A., Grunwald, T., Morgenstern, K., Pilegaard, K., Rebmann, C., Snijders, W., Valentini, R., Vesala, T., 2000. Estimates of the annual net carbon and water exchange of European forests: the EUROFLUX methodology. Adv. Ecol. Res. 30, 113-174.

Baldocchi, D., Falge, E., Gu, L., Olson, R., Hollinger, D., Running, S., Anthoni, P., Bernhofer, C., Davis, K., Evans, R., Fuentes, J., Goldstein, A., Katul, G., Law, B. Lee, X., Malhi, Y., Meyers, T., Munger, W., Oechel, W., Paw, K.T., Pilegaard, K. Schmid, H.P., Valentini, R., Verma, S., Vesala, T., Wilson, K., Wofsy, S., 2001. Fluxnet: a new tool to study the temporal and spatial variability of ecosystem-scale carbon dioxide, water vapor, and energy flux densities. Bull. Am. Meteorol. Soc. 82, 2415-2434.

Baldocchi, D., 2003. Assessing the eddy covariance technique for evaluating carbon dioxide exchange rates of ecosystems: past, present and future. Global Change Biol. 9, 479-492.

Bowling, D.R., Sargent, S.D., Tanner, B.D., Ehleringer, J.R., 2003. Tunable diode laser absorption spectroscopy for stable isotope studies of ecosystem-atmosphere $\mathrm{CO}_{2}$ exchange. Agric. For. Meteorol. 118, 1-19.

Burba, G., McDermitt, D.K., Anderson, D.J., Furtaw, M.D.. Eckles, R.D., 2010, Novel design of an enclosed $\mathrm{CO}_{2} / \mathrm{H}_{2} \mathrm{O}$ gas analyser for eddy covariance flux measurements. Tellus B 62, 743-748.

Burba, G., Schmidt, A., Scott, R.L., Nakai, T., Kathilankal, J., Fratini, G., Hanson, C., Law, B., McDermitt, D.K., Eckles, R., Furtaw, M., Velgersdyk, M., 2012. Calculating $\mathrm{CO}_{2}$ and $\mathrm{H}_{2} \mathrm{O}$ eddy covariance fluxes from an enclosed gas analyzer using an instantaneous mixing ratio. Global Change Biol. 18, 385-399.

Coyle, M., Nemitz, E., Storeton-West, R., Fowler, D., Cape, J.N., 2009. Measurements of ozone deposition to a potato canopy. Agric. For. Meteorol. 149 (3-4), 655-666.

Ermel, M., Oswald, R., Mayer, J.C., Moravek, A., Song, G., Beck, M., Meixner, F.X., Trebs, I., 2013. Preparation methods to optimize the performance of sensor discs for fast chemiluminescence ozone analyzers. Environ. Sci. Technol. 47, 1930-1936.

Fares, S., Weber, R., Park, J.H., Gentner, D., Karlik, J., Goldstein, A.H., 2012. Ozone deposition to an orange orchard: partitioning between stomatal and non-stomatal sinks. Environ. Pollut. 169, 258-266.

Feng, Z., Kobayashi, K., Ainsworth, E.A., 2008. Impact of elevated ozone concentration on growth, physiology, and yield of wheat (Triticum aestivum L.): a meta-analysis. Global Change Biol. 14 (11), 2696-2708.

Fratini, G., Ibrom, A., Arriga, N., Burba, G., Papale, D., 2012. Relative humidity effects of water vapour fluxes measured with closed-path eddy-covariance systems with short sampling lines. Agric. For. Meteorol. 165, 53-63.

Galbally, I.E., 1971. Ozone profiles and ozone fluxes in the atmospheric surface layer. Q. J. R. Meteorol. Soc. 97 (411), 18-29.

Griffis, T.J., Sargent, S.D., Baker, J.M., Lee, X., Tanner, B.D., Greene, J., Swiatek, E., Billmark, K., 2008. Direct measurement of miosphere-atmosphere isotopic $\mathrm{CO}_{2}$ exchange using the eddy covariance technique. J. Geophys. Res. 11, 3, http://dx.doi.org/10.1029/2007JD009297

Grünhage, L., Hänel, H.D., Jäger, H.J., 2000. The exchange of ozone between vegetation and atmosphere: micrometeorological measurement techniques and models. Environ. Pollut. 109, 373-392.

Güsten, H., Heinrich, G., Schmidt, R.W.H., Schurath, U., 1992. A novel ozone sensor for direct eddy flux measurements. J. Atmos. Chem. 14, 73-84.

Güsten, H., Heinrich, G., 1996. On-line measurements of ozone surface fluxes: part I. Methodology and instrumentation. Atmos. Environ. 30 (6), 897-909.

Ibrom, A., Dellwik, E., Flyvbjerg, H., Jensen, N.O., Pilegaard, K., 2007. Strong low-pass filtering effects on water vapour flux measurements with closed-path eddy correlation systems. Agric. For. Meteorol. 147, 140-156.

Kaimal, J.C., Wyngaard, J.C., Izumi, Y., Cote, O.R., 1972. Spectral characteristics of surface layer turbulence. Q. J. R. Meteorol. Soc. 98, 653-689.

Kaimal, J.C., Finnigan, J., 1994. Atmospheric Boundary Layer Flows: Their Structure and Measurement. Oxford University Press, New York/Oxford.

Kurpius, M.R., McKay, M., Goldstein, A.H., 2002. Annual ozone deposition to a Sierra Nevada ponderosa pine plantation. Atmos. Environ. 36 4503-4515.

Lamaud, E., Carrara, A., Brunet, Y., Lopez, A., Druilhet, A., 2002. Ozone fluxes above and within a pine forest canopy in dry and wet conditions. Atmos. Environ. 36, $77-88$.

Lamaud, E., Loubet, B., Irvine, M., Stella, P., Personne, E., Cellier, P., 2009. Partitioning of ozone deposition over a developed maize crop between stomatal and non-stomatal uptakes using eddy-covariance flux measurements and modelling. Agric. For. Meteorol. 149 (9), 1385-1396.

Lenschow, D.H., Raupach, M.R., 1991. The attenuation of fluctuations in scalar concentrations through sampling tubes. J. Geophys. Res. Atmos. 96 (D8), 15259-15268.

Leuning, R., Unsworth, M.H., Neumann, H.N., King, K.M., 1979. Ozone fluxes to tobacco and soil under field conditions. Atmos. Environ. 13, 1155-1163.

Leuning, R., Moncrieff, J., 1990. Eddy-covariance $\mathrm{CO}_{2}$ flux measurements using open-path and closed-path $\mathrm{CO}_{2}$ analysers - corrections for analyser water vapour sensitivity and damping of fluctuations in air sampling tubes. Boundary-Layer Meteorol. 53, 63-76.

Leuning, R., King, K.M., 1992. Comparison of eddy-covariance measurements of $\mathrm{CO}_{2}$ fluxes by open- and closed-path $\mathrm{CO}_{2}$ analysers. Boundary-Layer Meteorol. $59,297-311$.

LI-COR, 2013. Instruction Manual of EddyPro ${ }^{\circledR}$ Eddy Covariance Software. <ftp:// ftp.licor.com/perm/env/EddyPro/Manual/EddyPro4_User_Guide.pdf/>.

Loubet, B., Cellier, P., Fléchard, C., Zurfluh, O., Irvine, M., Lamaud, E., Stella, P., Roche, R., Durand, B., Flura, D., Masson, S., Laville, P., Garrigou, D., Personne, E., Chelle, M., Castell, J.F., 2013. Investigating discrepancies in heat, $\mathrm{CO}_{2}$ fluxes and $\mathrm{O}_{3}$ deposition velocity over maize as measured by the eddy-covariance and the aerodynamic gradient methods. Agric. For. Meteorol. 169, 35-50.

Massman, W.J., 1991. The attenuation of concentration fluctuations in turbulent-flow through a tube. J. Geophys. Res. 96, 5269-5273.

Massman, W.J., 2000. A simple method for estimating frequency response corrections for eddy covariance systems. Agric. For. Meteorol. 104, 185-198.

Massman, W.J., Lee, X., 2002. Eddy covariance flux corrections and uncertainties inlong-term studies of carbon and energy exchanges. Agric. For. Meteorol. 113 $121-144$.

Massman, W.J., Clement, R., 2004. Uncertainty in eddy covariance flux estimatesresulting from spectral attenuation. In: Lee, X., Massman, W.J., Law, B.E. (Eds.), Handbook of Micrometeorology: A Guide for Surface Flux Measurement and Analysis. Kluwer Academic Publishers, Dordrecht, The Netherlands.

Mayer, J.C., Bargsten, A., Rummel, U., Meixner, F.X., Foken, T., 2011. Distributed Modified Bowen Ratio method for surface layer fluxes of reactive and non-reactive trace gases. Agric. For. Meteorol. 151, 655-668.

Mills, G., Pleijel, H., Braun, S., Büker, P., Bermejo, V., Calvo, E., Simpson, D., 2011. New stomatal flux-based critical levels for ozone effects on vegetation. Atmos. Environ. 45 (28), 5064-5068.

Moncrieff, J.B., Massheder, J.M., De Bruin, H., Elbers, J., Friborg, T., Heusinkveld, B., Kabat, P., Scott, S., Søgaard, H., Verhoef, A., 1997. A system to measure surface fluxes of momentum, sensible heat, water vapor and carbon dioxide. J. Hydrol. 188-189, 589-611.

Moore, C.J., 1986. Frequency response corrections for eddy correlation systems. Boundary-Layer Meteorol. 37, 17-35.

Muller, J.B.A., Coyle, M., Fowler, D., Gallagher, M.W., Nemitz, E.G., Percival, C.J., 2009. Comparison of ozone fluxes over grassland by gradient and eddy covariance technique. Atmos. Sci. Lett. 10 (3), 164-169.

Muller, J.B.A., Percival, C.J., Gallagher, M.W., Fowler, D., Coyle, M., Nemitz, E., 2010. Sources of uncertainty in eddy covariance ozone flux measurements made by dry chemiluminescence fast response analysers. Atmos. Meas. Tech. 3 (1), 163-176.

Musselman, R., Lefohn, A., Massman, W., Heath, R., 2006. A critical review and analysis of the use of exposure- and flux-based ozone indices for predicting vegetation effects. Atmos. Environ. 40 (10), 1869-1888.

Pleijel, H., Danielssona, H., Ojanper, K., 2004. Relationships between ozone exposure and yield loss in European wheat and potato - a comparison of concentration- and flux-based exposure indices. Atmos. Environ. 38 (15), 2259-2269.

Ray, J.D., Stedman, D.H., Wendell, G.J., 1986. Fast chemiluminescent method for measurement of ambient ozone. Anal. Chem. 58 598-600.

Rummel, U., Ammann, C., Gut, A., Meixner, F.X., Andreae, M.O., 2002. Eddy covariance measurements of nitric oxide flux within an Amazonian rain forest. J. Geophys. Res. 107, 8050, http://dx.doi.org/10.1029/2001JD000520

Sun, X.M., Zhu, Z.L., Wen, X.F., Yuan, G.F., Yu, G.R., 2006. The impact of averaging period on eddy fluxes observed at ChinaFLUX sites. Agric. For. Meteorol. 137, 188-193.

Turnipseed, A.A., Burns, S.P., Moore, D.J.P., Hu, J., Guenther, A.B., Monson, R.K., 2009. Controls over ozone deposition to a high elevation subalpine forest. Agric. For. Meteorol. 149 (9), 1447-1459.

Wang, X.K., Manning, W., Feng, Z.Z., Zhu, Y.G., 2007. Ground-level ozone in China: distribution and effects on crop yields. Environ. Pollut. 147 (2), $394-400$.

Webb, E.K., Pearman, G.I., Leuning, R., 1980. Correction of flux measurements for density effects due to heat and water vapour transfer. Q. J. R. Meteorol. Soc. $106,85-100$

Wohlfahrt, G., Hörtnagl, L., Hammerle, A., Graus, M., Hansel, A., 2009. Measuring eddy covariance fluxes of ozone with a slow-response analyser. Atmos. Environ. 43, 4570-4576.

Yu, G.R., Wen, X.F., Sun, X.M., Tanner, B.D., Lee, X., Chen, J.Y., 2006. Overview of ChinaFLUX and evaluation of its eddy covariance measurements. Agric. For. Meteorol. 137, 125-137. 
Yushkov, V., Oulanovsky, A., Lechenuk, N., Roudakov, I., Arshinov, K., Tikhonov, F., Stefanutti, L., Ravegnani, F., onafe, U., Geordiadis, T., 1999. A chemiluminescent analyzer for stratospheric measurements of the ozone concentration (FOZAN). J. Atmos. Oceanic Technol. 16, 1345-1350.

Werle, P., Mucke, R., Slemr, F., 1993. The limits of signal averaging in atmospheric trace-gas monitoring by tunable diode-laser absorption-spectroscopy (TDLAS). Appl. Phys. B 57 (2), 131-139.
Zahn, A., Weppner, J., Widmann, H., Schlote-Holubek, K., Burger, B., Kühner, T., Franke, H., 2012. A fast and precise chemiluminescence ozone detector for eddy flux and airborne application. Atmos. Meas. Tech. 5 (2), 363-375. 